Outros Tempos, vol. 19, n. 33, 2022, p. 362-382. ISSN: 1808-8031

\title{
http://dx.doi.org/10.18817/ot.v19i33.924
}

\section{Entrevista: Carlos Garriga. Dossiê História da Justiça: Das independências aos Estados americanos $^{1}$}

\author{
RENATA SILVA FERNANDES \\ ORCID: https://orcid.org/0000-0002-9861-5913 \\ Doutora em História pela UFJF \\ Professora da Universidade Federal de Goiás \\ Goiânia/Goiás/Brasil \\ renata_fernandes@ufg.br
}

Carlos Garriga, doutor em Direito pela Universidad de Salamanca, foi professor titular da Universidad Autónoma de Madrid e, desde 2004, é catedrático em História do Direito na Universidad del País Vasco. Suas linhas de investigação se concentram na História da Justiça (séculos XIII-XVIII), no Constitucionalismo Hispânico e na transição da ordem jurídico-política tradicional às ordens legais no espaço ibero-americano. Autor de uma série de artigos e de livros - incluindo-se, entre eles, La Audiencia y las Chancillerías castellanas (1371-1525). Historia política, régimen jurídico y práctica institucional (1994); Historia y Constitución. Trayectos del constitucionalismo hispano (2010); e, juntamente com Marta Lorente, Cádiz, 1812. La Constitución jurisdicional (2007) -, suas obras são bem conhecidas pelo público acadêmico brasileiro. Vinculado a diversos projetos de pesquisa internacionais, no Brasil, foi, ainda, professor visitante na Universidade de São Paulo, na Universidade Federal de São Paulo e na Universidade Federal do Espírito Santo e, atualmente, integra a equipe do Diretório de Pesquisa do CNPq Opinio Doctorum. Nesta entrevista, Garriga discute questões teórico-metodológicas e temáticas sobre a história do direito e da justiça, assim como suas implicações no âmbito dos estudos de Antigo Regime e do Oitocentos.

OT. Por lo menos, desde la década de 1980, a raíz de trabajos como los de Bartolomé Clavero y António Manuel Hespanha, hemos presenciado una profunda renovación en los estudios historiográficos sobre el pasado colonial de las Américas, que también ha impactado las investigaciones sobre las independencias y los procesos de formación de nuevos Estados en el siglo XIX. Esta renovación, al parecer, está directamente vinculada a nuevas perspectivas sobre el derecho y a un diálogo más intenso entre la historia del derecho y las historias política, social, etc. ¿Cómo comprende las nociones de “derecho” y de “justicia” en el

\footnotetext{
${ }^{1}$ Entrevista realizada por Renata Silva Fernandes, em 4 de dezembro de 2021.
} 
Outros Tempos, vol. 19, n. 33, 2022, p. 362-382. ISSN: 1808-8031

horizonte de la historiografía y las formas a partir de las cuales los historiadores las han incorporado en sus investigaciones?

Carlos Garriga: Para responder esta pregunta quiero partir de una idea ajena, que ya he utilizado otras veces en algunos trabajos míos de carácter metodológico. Es de Francisco Tomás y Valiente, excelente historiador del derecho y también magistrado del Tribunal Constitucional español, asesinado por la banda terrorista ETA en 1996. Veinte años antes, en 1976, había escrito esta frase: "El concepto que cada historiador del Derecho ha tenido y tiene acerca de la historia del derecho ha dependido y depende en primer término, aunque no siempre se reconozca así, de su propio concepto del Derecho"². El punto me parece muy importante, porque hablar de "la historia del derecho", así, en general, conduce a pocos resultados: hay obviamente diferentes maneras de afrontar la historia del derecho y estas maneras dependen primariamente, si creemos, como yo creo, que Tomás y Valiente tiene razón, del concepto que se tenga del derecho. Cuando él escribía esto, a mediados de los años 70, hace ya por tanto 45 años, los historiadores del derecho más conscientes o más comprometidos con su trabajo, sostenían una concepción por así decir vicaria del derecho. Vicaria en el sentido de entender que el derecho no da de sí razón suficiente, que el derecho es un sector, digamos así, de la realidad, que requiere del concurso de otros sectores, ubicados en la parte económica, social y política de la realidad, para ser explicado. Y ahí la historiografía jurídica priorizaba la relación entre el derecho y el poder para entender que el derecho es primariamente expresión de poder.... Este camino metodológico lleva a una suerte de historia social del derecho, que es la concepción a la que efectivamente estaban llegando entonces los mejores historiadores del derecho, como Tomás y Valiente. Y de eso se hablaba mucho, este es un tópico frecuentemente cultivado por la historiografía de la segunda mitad de los años 70 y comienzos de los 80: historia del derecho e historia social. Además de Tomás y Valiente, Hespanha tiene un breve libro, uno de sus primeros libros, que se ocupa de esto, y otro tanto Clavero, por citar a los dos autores que mencionas expresamente en tu pregunta. Este es, por otro lado, el contexto en el que yo inicié mi formación, bajo el magisterio de Benjamín González Alonso en la Salamanca de los ya lejanos años 80, y en ese contexto había desde luego mucho diálogo entre los historiadores del derecho y los cultivadores de otras disciplinas históricas, particularmente bajo el ancho paraguas de la entonces llamada, con un nombre que aún hoy algunos usan, "historia de las instituciones político-administrativas". Yo creo que

\footnotetext{
2 TOMÁS Y VALIENTE, Francisco. Historia del Derecho e Historia. En: Once ensayos sobre la Historia. Madrid: Fundación Juan March, Rioduero, 1976. p. 161-181.
} 
Outros Tempos, vol. 19, n. 33, 2022, p. 362-382. ISSN: 1808-8031

había una convivencia fructífera entre estas historiografías. Por recurrir a algún recuerdo personal, cuando iba al Archivo de Simancas a estudiar las visitas de las Chancillerías, que fue el tema de mi tesis doctoral, mis interlocutores eran quienes estaban estudiando otras instituciones o aparatos de gobierno y de justicia, no necesariamente, y de hecho a menudo no, desde la historia del derecho sino en otros ámbitos historiográficos. Este era un espacio de diálogo fructífero y, creo, mutuamente enriquecedor.

Sin embargo, este camino, que partiendo de una concepción vicaria del derecho conducía a una historia social del derecho, yo creo que se obturó a partir de los años 80, como efecto del llamado, y ciertamente no exclusivo de la historia del derecho, giro cultural. A vueltas de este giro se hace evidente que el derecho forma parte de la cultura (en el sentido de conducta socialmente aprendida) y como tal es inseparable de su entorno social. El derecho es una dimensión de la sociedad, sin que sea a priori aislable para considerar que depende de estos o aquellos factores. Constituye un punto de vista, una perspectiva, sobre el mundo social. Me parece que esto es de la máxima importancia. Considerar que el derecho forma parte de la cultura significa primero que nada admitir que no hay universales jurídicos, como no hay universales antropológicos; que conocer lo que sea derecho aquí o allá exige, por una parte, prescindir de cualquier preconcepción acerca de lo que signifique la palabra derecho; y al hacer esto, por otra parte, está abocándose al mismo tiempo a construir, a dotarse de instrumentos heurísticos, de una metodología apta para captar lo que sea derecho en cada experiencia histórica dada. Creo que esto lo cambia todo.

Esta manera de concebir las cosas, esta idea de que el derecho hace parte de la cultura y constituye, ni más ni menos, una dimensión relevante del mundo social, que solo es concebible en su propio contexto de producción, cambia de raíz la concepción y la práctica de la historia del derecho. Me parece que esta es la gran aportación historiográfica de autores como Bartolomé Clavero, António Manuel Hespanha o Pietro Costa, y también de otros historiadores que no lo son del derecho, si hablamos de su adscripción disciplinar, como Pablo Fernández Albaladejo, por poner un ejemplo que a mí me parece especialmente relevante. Su gran aportación, digo, es, por un lado, concebir que hay otros mundos jurídicos distintos del nuestro, que nuestro mundo jurídico no es simplemente resultado de una evolución inevitable y continuista, de una secuencia ininterrumpida en el curso del tiempo, sino que es producto justamente de una ruptura, de una discontinuidad que separa nuestro presente de un pasado inevitablemente, ineluctablemente diferente del nuestro.

Esa idea de alteridad es fundamental: la convicción de que hay otros mundos distintos del nuestro. En esta renovación cultural mucho tuvieron que ver los desarrollos de la 
Outros Tempos, vol. 19, n. 33, 2022, p. 362-382. ISSN: 1808-8031

antropología, como sus mismos protagonistas han destacado. António Manuel Hespanha, por ejemplo, lo cuenta muy bien en el arranque de su libro Panorama histórico da cultura jurídica europeia (1997-1998) ${ }^{3}$, evocando el proceso de cambio que se estaba dando desde finales de los años 70 y en el curso de los 80 . La primera clave es, por tanto, alteridad: la idea de que existen otras culturas jurídicas, que por distintos del nuestro nos son difícilmente accesibles.

Y la segunda gran aportación es justamente la elaboración de instrumentos, de herramientas para acceder a esos otros mundos distintos del nuestro, para reconstruir esas otras maneras de ver, de concebir las cosas en términos jurídicos, las dimensiones jurídicas de los mundos sociales “otros", por situados en el pasado de nuestro presente. Bartolomé Clavero, uno de sus principales artífices, lo expresa hablando de la reconstrucción de la antropología política de la sociedad europea altomoderna a través de su jurisprudencia, más o menos literalmente. La idea es, en todo caso, reconstruir una antropología distinta, y hacerlo justamente, esa es la apuesta metodológica, leyendo a los juristas, por entender que en su obra, en la jurisprudencia, se encuentran los saberes más consensuados, más consolidados, acerca de este universo social: juristas y teólogos o teólogos y juristas, en realidad, que van muy a la par, pues unos y otros se presuponen y se muestran en sus textos como enredados. Por recurrir a un expediente clásico, si un intelectual persa me preguntase hoy qué libros debería leer para comprender nuestra sociedad, yo no le recomendaría libros de derecho: creo que nadie pensaría hoy que los libros de derecho civil, pongamos por caso, sean los que de manera preferente expliquen la sociedad actual. Sin embargo, en las sociedades que llamamos genéricamente d'ancien régime creo que sí: los libros de derecho contenían entonces las claves del orden social; en ellos se encontraban los saberes más consensuados acerca del hombre, la sociedad, el poder. Cuando tú abres una obra como La política para corregidores y señores de vasallos, por citar una muy conocida y muy leída por los historiadores, rápidamente observas que [Jerónimo] Castillo de Bobadilla no trata solamente de los corregidores, es decir, del juez ordinario: quién lo nombra, con qué condiciones o requisitos, cuáles son sus funciones, responsabilidades..., en fin, los diferentes aspectos del oficio; sino que habla del mundo del que hace parte el corregidor en su conjunto y ese mundo está perfectamente reflejado en sus páginas. Lo pone bien de relieve Benjamín González Alonso

\footnotetext{
${ }^{3}$ HESPANHA, António Manuel. Panorama histórico da cultura jurídica europeia. Lisboa: Europa-América, 1997. Consultar también: HESPANHA, António Manuel. Cultura jurídica europeia: síntese de um milênio. Imprenta: Florianópolis, Boiteux, 2005.
} 
Outros Tempos, vol. 19, n. 33, 2022, p. 362-382. ISSN: 1808-8031

en su estudio preliminar a la edición facsimilar de la Política, publicada a finales de los años '70.

Todo esto me parece una aportación decisiva de la historiografía que suele llamarse crítica del derecho: constatar la alteridad del pasado y dotarse de medios para reconstruir esas otras culturas en términos normativos, subrayando la importancia de la jurisprudencia a este respecto. Este es el camino a seguir para reconstruir la dimensión jurídica de las sociedades que podemos llamar tradicionales, las sociedades de Antiguo Régimen (englobando la baja edad media y la edad moderna), primero que nada haciendo especial énfasis en su concepción muy diferente del derecho, que solemos llamar jurisdiccionalismo o concepción jurisdiccional (de iuris dictio, o sea, dictio iuris: decir, declarar el derecho), porque entiende el derecho como un orden declarativo a partir de principios indisponibles, en la medida que radicados en el campo sagrado de la religión. Sobre esta base se explica bien la distinta comprensión del poder político y del derecho, la esencial subordinación de aquél a éste, la composición pluralista del orden normativo, su configuración jurisprudencial,... En fin, las características todas de los órdenes jurídico-político tradicionales.

En fin, creo sinceramente que todos estos son puntos de no retorno: saberes o adquisiciones que me parece difícilmente reversibles; que son, bien al contrario, bases sólidas para reconstruir integralmente aquellas sociedades.

En el plano que a mí me toca más directamente, esto es lo que me lleva a hablar de justicia de jueces, para expresar la idea de que la clave de la justicia en el mundo pre-moderno no reside en las leyes sino que está en los mismos jueces, en el sentido de que en un caso dado lo que sea derecho no depende de lo que diga tal o cual disposición normativa de la autoridad política, sino de lo que el juez entienda que es derecho en atención a las circunstancias del caso controvertido, declarando un orden normativo que incluye pero excede con mucho a las disposiciones del poder político. Así que lo que llamamos administración de la justicia no consiste en la aplicación de leyes sino en la declaración del derecho, que es diferente. Las claves del aparato judicial no pasan por la vinculación del juez a la ley, sino que radican en el comportamiento justo, por ajustado al orden, del juez. Esto lleva a concentrar las garantías de la justicia en la persona y no en la decisión de los jueces, es decir, en aquellos procedimientos orientados a asegurar su comportamiento justo (su posición imparcial: recusación y responsabilidad, básicamente), más que la correcta aplicación del derecho (como la motivación de sentencias).

En fin, desde esta perspectiva todo se reubica. Aunque hoy seguimos cultivando el campo judicial prácticamente con los mismos términos (juez, juicio, etc.), estos cobran sentidos muy 
Outros Tempos, vol. 19, n. 33, 2022, p. 362-382. ISSN: 1808-8031

diferentes en función del contexto normativo. Como digo, todo esto: jurisdiccionalismo, pluralismo normativo (multinormatividad, se puede decir también, introduciendo un matiz algo distinto), jurisprudencia u orden jurisprudencial, etc., todos estos son para mí puntos de no retorno.

Sobre estas otras bases tenemos hoy también un espacio compartido y mantenemos un diálogo fructífero con historiadores que no se adscriben disciplinarmente a la historia del derecho, que es al que haces principalmente referencia en tu pregunta, y que, naturalmente, no se circunscribe al período del Antiguo Régimen - a la época colonial, si hablamos de América Latina-, sino que se prolonga largamente en el curso del siglo XIX, en la medida que la ruptura con aquel mundo fue muy complicada y lenta. Ese diálogo además está explorado: quizá merece la pena citar aquí un número monográfico extenso que la revista argentina PolHis (nombre abreviado) dedicó el año 2012 a estas cuestiones ${ }^{4}$.

Creo que estos enfoques delimitan un espacio de diálogo no solo posible, sino también necesario. Quiero decir que cualquier diálogo debe partir de la convicción compartida (desde diferentes ángulos historiográficos) de la alteridad de las sociedades pasadas, que es la que justifica la necesidad de dotarse de instrumentos idóneos para conocerlos. Yo suelo expresar esto diciendo que la posición epistemológica del historiador del derecho, y creo que de cualquier historiador, resulta de la confluencia de dos puntos de vista diferentes sobre su objeto, que conllevan estrategias de investigación y técnicas expositivas muy distintas entre sí: un punto de vista posterior, obviamente inherente a la condición de historiador, que siempre mira desde después (va del presente al pasado) y tiende a construir genealogías; y un punto de vista externo, que mira desde fuera (va de fuera hacia dentro) y tiende a construir "mundos", espacios de sentido, marcos de significado. La primera estrategia privilegia la diacronía (del pasado al presente), mientras que la segunda nos sitúa en clave sincrónica (el pasado o el presente). Pero el historiador se sitúa en la confluencia entre ambas perspectivas: es el sujeto que, a efectos cognitivos, adopta un punto de vista posterior y externo respecto de lo acontecido y queda condicionado por esta posición epistemológica.

Así resumiría yo todo este planteamiento en clave metodológica, porque a partir de aquí, de aquellos puntos que decía de no retorno, creo que se puede plantear, y ese me parece que es también el sentido de tu pregunta, por un lado, qué retos tiene hoy la historia del derecho. Y por otro lado, en qué medida esos retos o tareas de futuro son o no compartidas por la historiografía que no se identifica o autodefine como jurídica -aunque se ocupe de la

\footnotetext{
${ }^{4}$ Disponible en: http://polhis.com.ar/archivo/polhis10/.
} 
Outros Tempos, vol. 19, n. 33, 2022, p. 362-382. ISSN: 1808-8031

dimensión jurídica de las sociedades pasadas. Entonces, ¿qué retos tiene hoy, a mi juicio, la historia del derecho? Me parece que esta perspectiva, digamos cultural, lo que podemos llamar historia cultural del derecho -quizá tenía que haberlo dicho antes: ese desarrollo que tiene lugar a partir de los años 80 y suele llamarse historia crítica del derecho, creo yo que merece tener como nombre más propio "historia cultural del derecho"; esta perspectiva, digo, es irrenunciable: nos enseña una manera de acceder a otras culturas, descubriéndonos su gramática, reconstruyendo su léxico, etc. Pero también me parece que es insuficiente, en el sentido de que podemos y creo que debemos dar mayor cabida, sobre esta base, a la complejidad y dinámica social -como, por otro lado, los propios artífices principales de este giro no han dejado de advertir. Por acudir a términos consolidados de la historia social, tal como yo lo veo se trataría de encontrar la manera de hacer una historia del derecho desde abajo (por usar los términos que puso en circulación E. P. Thompson en los años '70). Creo que para esto es imprescindible asumir, en primerísimo lugar, que la cultura en su sentido más lato es simplemente -como ya apunté antes- conducta socialmente aprendida y por tanto en sentido propio toda historia cultural es historia social. Pues bien, para ensayar esa historia desde abajo, me parece que los historiadores del derecho más conscientes y consistentes aportan hoy una noción clave cuando enfatizan la idea de historia local o de localización. Este último término lo encontramos en algunos textos de los mismos autores que venimos citando, Clavero o Hespanha, hacia los años 2012-2013, pero es Alejandro Agüero, nuestro colega argentino, quien más y mejor ha trabajado para darle un sentido teórico e historiográfico definido. Y yo mismo, en un trabajo que dediqué recientemente a la memoria de António Manuel Hespanha titulado Historia y derecho. Perspectivas teóricas para una historia localizada del derecho ${ }^{5}$, trato de fundamentar teóricamente cómo creo que debemos afrontar una historia del derecho desde abajo, aunque no use ahí este último sintagma. Cuando hablamos de localización lo que pretendemos es justamente enfatizar el papel de las agencias y de los procesos de intermediación locales en la determinación de lo que sea derecho, así que nos interesa no tanto lo que "tenga en la cabeza" (valga por gráfica la expresión) quien desde posiciones de poder dispone en términos normativos, la "intención del legislador", sino las constelaciones cognitivas y axiológicas, lo que "tengan en la cabeza" quienes están sujetos a las reglas: los que ocupan en el conjunto social la posición de obligados a cumplirlas, sus

\footnotetext{
${ }^{5}$ Se refiere a: GARRIGA, Carlos. Historia y Derecho: perspectivas teóricas para una historia localizada del Derecho. En: ACHÓN INSAUSTI, José Ángel; IMIZCOZ BEÚNZA, José María (eds.). Discursos y contradiscursos en el proceso de la modernidad (siglos XVI-XIX). Madrid: Sílex, 2019. p. 67-168.
} 
Outros Tempos, vol. 19, n. 33, 2022, p. 362-382. ISSN: 1808-8031

destinatarios. Porque cumplirlas significa comprenderlas, es decir, atribuirles uno u otro significado.

Así entendida, la localización nos dirige especialmente hacia los escenarios judiciales, pero no queda necesariamente circunscrita a las comunidades locales (en el sentido de vecinales). Lo uno y lo otro: interesa el momento en que se determina efectivamente lo que sea derecho en atención a las circunstancias locales, pero no necesariamente en los mismos espacios locales, sino también en aquellos tribunales que tienen la precisa función de decidir en último término qué sea derecho. Esto es muy claro en los ámbitos coloniales, al menos en el caso hispano, donde la actividad litigiosa de los indígenas en su condición de indios fue siempre tan intensa. Es en este ámbito judicial donde mejor puede seguirse la articulación normativa e institucional entre el orden global de impronta católica y vocación hegemónica de la Monarquía (la tradición jurídica católica) y la miríada de circunstancias y factores locales que la agencia indígena pugna por visibilizar y hacer valer. Ese es el punto de intersección entre una y otra. El objetivo en cualquier caso, por lo menos el mío en este momento, es como digo hacer una historia del derecho desde abajo, tomando en consideración no solo lo que dicen los juristas en sus obras, sino también lo que expresan con los medios a su alcance, como la documentación judicial refleja, quienes viven y actúan desde otras posiciones bajo un mismo orden institucionalizado.

Esto me lleva a lo segundo, ¿cómo entablar sobre esta base relaciones con otras historiografías? Me parece que un buen punto de partida sería asumir con todas sus consecuencias que el derecho hace parte de la cultura y no dar por supuesto a priori, como a menudo parece ser el caso, que el derecho ocupa un sector delimitado de la realidad social, que se encuentra en dependencia de otros (como el económico o el político) y que tomarlo en consideración para el estudio de esta última es poco menos que optativo. Frente a cualquier concepción vicaria del derecho, entiendo que éste debe ser visto como una dimensión de o perspectiva sobre la realidad social, que es por tanto inseparable de ésta. El derecho es imprescindible para comprender el orden social. Claro que este imbrica diferentes conjuntos de reglas, pero su tipología y relaciones no pueden determinarse a priori... Me parece un mal punto de partida considerar que el derecho es de cualquier modo separable de su entorno social y prescindible para el conocimiento de éste: el derecho como cosa de juristas, que puede ser obviado...

Este parece ser un punto de vista extendido entre algunos cultivadores de la historia social de la justicia, corriente historiográfica de notable desarrollo y potentes realizaciones, en muchas ocasiones con resultados estupendos, pero difícilmente sostenible en el plano teórico. El 
Outros Tempos, vol. 19, n. 33, 2022, p. 362-382. ISSN: 1808-8031

nombre resultaría casi redundante, desde el momento que la justicia hace obviamente parte del mundo social, si no fuera porque lo que aparentemente quiere decirse es historia no jurídica de la justicia, que se concreta, y por eso lo traigo aquí a colación, en la práctica prescindencia de las fuentes inmediatamente derivadas de la actividad de los juristas, para centrarse en la documentación archivística, como si esta facilitase de suyo un mejor o más directo acceso a la realidad histórica y renunciar a la obra de los juristas autorizase o equivaliese a prescindir del derecho y su problemática; en definitiva, como si unos y otros textos - es importante no olvidar que todos los son y como tales deben ser decodificados- no formasen parte del mismo mundo y pudiera separarse la lectura de los unos y la lectura de los otros... Creo que ninguna de estas suposiciones puede sostenerse fundadamente. Tomemos la figura documental principal del ámbito judicial, que es el pleito: ¿acaso puede entenderse sin conocer sus reglas, las reglas que estaban obligados a seguir y de uno u otro modo conocían los agentes (letrados, prácticos, pleiteantes, etc.)? Recientemente leía en un texto de Foucault que tiene ya la friolera de cincuenta años, el último en publicarse de sus cursos en el Collège de France (1971-1972), que lo que caracteriza la justicia, el mundo judicial, es "el desarrollo reglado de un litigio". Permíteme que lea: "lo que define el orden jurídico es la manera de enfrentarse, la manera de luchar. La regla y la lucha, la regla en la lucha: eso es lo jurídico”. Y eso lo encontramos de la manera más sofisticada y articulada, indudablemente más erudita, en la jurisprudencia, las obras de los juristas, con todas sus discrepancias (que pueden llegar a ser inmensas, pero nunca tan hondas como para romper la unidad del orden en el que se inscriben).

Perspectivas como esta que comento, he hablado de la "historia social de la justicia" porque es el ejemplo que primero me viene, parecen partir de la idea de que la historia del derecho vale para proporcionar categorías normativas, sea históricas (como jurisdicción) o historiográficas (como justicia de jueces); pero no para el estudio de las prácticas, quizá por imputar a la disciplina las realizaciones de algunos de sus cultivadores. Para mí es muy obvio que, sea cual sea la adscripción disciplinar del historiador (social, del derecho u otras), se trata de superar esa ficticia división (en último término, teoría/práctica) e integrar el conocimiento de las fuentes en función del objeto, en este caso la justicia. Cada quien sabrá cómo se traduce esto en su caso. En el mío, la lectura de los juristas sirve a reconstruir un "mundo" un espacio de sentido, con su léxico y su gramática, el habitus en definitiva, que no pretende sustituir sino posibilitar el conocimiento - la comprensión, en sentido propio- de las dinámicas sociales: el uso que de aquellos hagan los sujetos, su agencia, en la composición de discursos y la articulación de prácticas. 
Outros Tempos, vol. 19, n. 33, 2022, p. 362-382. ISSN: 1808-8031

Si vamos a un campo de estudios al que me he acercado más de una vez, y que ahora está muy desarrollado, el campo de estudios sobre la corrupción, todo esto se aprecia muy claramente. A tenor de la última historiografía, pareciera que se puede distinguir (lo que para el caso significa prescindir) el discurso de los juristas sobre la corrupción de las prácticas sociales que podemos calificar o no, según el criterio que utilicemos, como corruptas. Me parece claro que es preciso integrar ambos frentes, a partir de una categoría, corrupción, que los juristas abordan y construyen con sumo detalle. Por descontado, ellos no son los únicos que hacen discursos sobre la corrupción, los propios juristas son conscientes de ello y presuponen otros lenguajes, pero todos están integrados como parte del orden normativo de base religiosa y expresión preferentemente jurídica que disciplinaba aquel mundo social.

Creo que me he extendido más de la cuenta, pero tu pregunta me ha ido guiando por estos derroteros.

OT. La "tradición jurídica católica" es una categoría recurrente en sus trabajos. En esta se coloca esfuerzos para conciliar aspectos diacrónicos y sincrónicos de los saberes jurídicos, una vez que se trata de acercar la fuerza histórica de la tradición a los modos de uso contingentes de aquellos que toman parte en su remodelación dentro de un orden católico. En este sentido, considerando que cualquier costumbre (consuetudo) inscrita en las sociedades católicas del Antiguo Régimen se refería a una metafísica continuamente actualizada bajo la competencia regulada frente a las autoridades en las diversas materias y materiales discursivos, ¿cómo observa las relaciones entre la tradición como "constante devenir de continuidad en conflicto" y un orden del tiempo destinado a encuadrar las dinámicas de la "cultura" en una perspectiva providencialista? En resumen, ¿cómo pensar el lugar del cambio en el ámbito de la "tradición jurídica", por ejemplo, en sociedades que desconocían las categorías posiluministas de "invención", “autor", “originalidad”, etc.?

Carlos Garriga: Es una pregunta muy interesante y difícil además de responder. Partamos de la "tradición jurídica católica", porque ese es el marco dentro del cual puedo ensayar una respuesta. Efectivamente, en los últimos años empleo con frecuencia la expresión "tradición jurídica católica", que no puede decirse que se encuentra muy difundida en la historiografía. Por supuesto, las ciencias sociales hablan constantemente de "tradición" y el campo "tradición jurídica" cuenta con una extensa bibliografía, debido por cierto más a juristas que a historiadores: han sido sobre todo los comparatistas, cultivadores del derecho comparado, quienes han trabajado en mayor medida esta noción en los últimos años, con la obra señera de 
Outros Tempos, vol. 19, n. 33, 2022, p. 362-382. ISSN: 1808-8031

Patrick Glenn como referencia ${ }^{6}$. Pero la rúbrica "tradición jurídica católica" específicamente no está especialmente tematizada. No digo yo que nadie la use, claro que no, pero hasta donde sé no ha sido especialmente considerada ni menos teorizada.

Y a mí me parece que debería, porque si asumimos que el orden pre-moderno (en el sentido de pre-contemporáneo) puede ser caracterizado como tradicional (básicamente porque cambia permaneciendo), entonces vale la pena indagar si podemos acotar un segmento de los espacios que están sujetos a órdenes de este tipo, acomunándolos bajo el calificativo de católicos. Me explico mejor: si no todos los órdenes tradicionales son sin más intercambiables, aun cuando todos compartan unas claves formales de funcionamiento similares (básicamente, repito, porque cambian permaneciendo), sería interesante indagar en qué medida pueden ser agrupados/distinguidos en razón de sus contenidos sustantivos.

Por mi parte, he intentado precisar de qué hablamos cuando hablamos de tradición o de tradición jurídica, no procurando una suerte de noción omnicomprensiva, empresa seguramente inabarcable o poco menos, sino por la vía de conectarla con otras categorías con las que se disputa el campo o entra en conflicto o está necesariamente en relación. La primera es cultura, tradición-cultura: hay un debate entre los comparatistas (que se dedican al estudio comparado de los órdenes jurídicos en el mundo presente) sobre si es preferible hablar de tradición jurídica o es preferible hablar de cultura jurídica... A mí me parece que ese es un debate poco fructífero realmente, una discusión que conduce a pobres resultados. Sigo el punto de vista de uno de los comparatistas aludidos, Pierre Legrand ${ }^{7}$, para quien tradición y cultura vienen a ser casi intercambiables, en el sentido de que la tradición sería la valencia o dimensión histórica de la cultura y la cultura sería la instanciación o dimensión contemporánea de la tradición. A fin de cuentas, cuando hablamos de tradición siempre hablamos de transmisión cultural, lo que implica delimitar una comunidad diacrónica (porque se extiende en el curso del tiempo) de participantes que comparten una serie de rasgos: valores, creencias, convicciones, criterios, que son propiamente definitorios: definen e identifican su tradición.

El segundo binomio que me parece interesante es tradición-cambio (o mudança, utilizando un término más comprensible desde el portugués). Me parece que planteadas las cosas en los términos recién dichos, el cambio, la mudança es inherente a la tradición. Lejos de ser estática, la tradición se caracteriza por cambiar de manera constante, justamente para

\footnotetext{
${ }^{6}$ GLENN, Patrick. Legal Traditions of the World. Sustainable Diversity in Law. New York: Oxford University Press, 2010.

7 Por ejemplo: LEGRAND, Pierre. Comparative Legal Studies and the Matter of Authenticity. Journal of Comparative Law, v. 1, n. 2, 2006, p. 365-460.
} 
Outros Tempos, vol. 19, n. 33, 2022, p. 362-382. ISSN: 1808-8031

mantener los principios (o creencias o valores...) que la definen, a pesar del cambio de las circunstancias en que se desenvuelven: la adaptación es completamente inherente a la tradición. Como antes decía, la tradición cambia permaneciendo: hasta donde alcanzo, no es concebible un mundo cualquiera que definamos como tradicional y sea además ajeno a la mudança. Creo que quienes no lo perciben así confunden tradición y tradicionalismo. En fin, esto nos llevaría a otras derivadas que no son ahora del caso.

Y por último, tradición-identidad me parece otra clave explicativa: en la medida en que la tradición se define a partir de ciertas ideas o creencias, valores o principios, toda comunidad que los asuma como propios funciona como una comunidad epistémica, definida precisamente por compartir o adherirse a unos mismos principios o valores e ideas o creencias. Así que, como dices en tu pregunta, podemos concebir la tradición como un devenir de continuidades en conflicto, que se desenvuelven mediante operaciones de inclusión/exclusión, llevadas a cabo por esta comunidad epistémica de participantes en la tradición.

La tradición proporciona, aglutina una serie de valores, de creencias, de mitos, en fin, de reglas compartidas, a partir de los cuales no solamente es posible, sino que es inevitable la discrepancia. En mis clases, siempre uso en este punto como ejemplo la Reforma Protestante, que introduce una quiebra sustancial en la tradición cristiana, sin enajenarse de ella, ni mucho menos. Me parece que este es un buen ejemplo para ilustrar la idea de continuidades en conflicto: valores y creencias, principios y reglas, transmitidos en textos que se mantienen como referente último y a partir de los cuales se producen desarrollos discrepantes. Así que puede ajustarse al esquema musical de "tema y variaciones", más o menos, creo que podría ser algo así. Y en el entendido de que cada tradición tiene sus propios dispositivos de validación: mecanismos de uno u otro tipo para determinar la validez de los desarrollos que la historia va deparando: por volver al ejemplo anterior y del lado católico, la Inquisición, por ejemplo, es un aparato institucional especialmente orientado a velar por la validez de unos discursos y prácticas frente a otros posibles.

Si concebimos así la tradición, con su dimensión jurídica, es claro que no todos los desarrollos son análogos e intercambiables, y de ahí que pueda plantearse cómo calificar la tradición jurídica que se desarrolla en el mundo o mundos que aquí nos interesan más, los mundos ibéricos. Y así, de primeras, visto el panorama, se nos aparecen dos grandes opciones: por un lado, tradición jurídica occidental, en la que suelen distinguirse dos grandes ramas: civil law y common law, que va en todo caso (digo, incluso circunscritos al civil law) mucho más allá de los mundos ibéricos y que, justamente por tan general, me parece muy 
Outros Tempos, vol. 19, n. 33, 2022, p. 362-382. ISSN: 1808-8031

poco sustancial. Y por otro lado, en el otro extremo, se puede hablar y se habla de una tradición jurídica latinoamericana, que sobre ser muy reciente es además para lo que aquí interesa anticipatoria, porque de una tal tradición como algo distinto y con características propias difícilmente podemos hablar antes de la época contemporáneo. De ahí que yo desemboque en la "tradición jurídica católica", que pretende además tomar en cuenta el peso absolutamente determinante que tiene la religión en las sociedades de antiguo régimen. En todo caso, creo que merecería la pena indagar seriamente si esta categoría es o no válida para el propósito caracterizador señalado, al lado de otras como colonialismo católico o constitucionalismo católico.

Como parte de este trabajo creo yo que estaría justamente la pregunta que tú haces, es decir, qué concepción del tiempo, qué orden del tiempo, si utilizamos la expresión de Krzystof Pomian, es propia de esta cultura. Aquí entra inmediatamente la escatología católica y demás nociones a las que hacías referencia también en esta pregunta. Por esta vía intentaríamos captar, acceder a su autorrepresentación del cambio y más en general del tiempo histórico: no la manera como cambia, sino la manera como los sujetos se representan el cambio (la mudança); cómo se piensa el cambio en un mundo en el que los discursos jurídico-políticos parten del siempre del "antes" (cómo eran los romanos, cómo eran los griegos), mientras que el punto de vista característico de la modernidad se sitúa siempre en el "después" y concibe el cambio en términos de ruptura de época; ser moderno, ha dicho alguien, es tener la convicción de que uno ya nunca más va a volver a ser ni griego ni romano (Gómez Ramos). Continuidad v. discontinuidad. En fin, como es sabido, es la idea que formula Koselleck con su dicotomía "espacio de experiencia" / "horizonte de expectativas" y su distinto juego en los mundos tradicional y moderno. Se trataría, en suma, de reconstruir estas distintas concepciones, pero esto no da cuenta de los cambios, sino de la percepción que de estos tienen los participantes.

Para aquello otro, para explicarse los cambios y dar cuenta de la discontinuidad, que para mí es prioritario y en esta pregunta creo interesa más, recuperaría la idea que hace un momento mencionaba sobre la posición epistémica del historiador, que en su condición de observador resulta de la confluencia entre punto de vista posterior y externo respecto de lo acontecido. Por esta vía creo que llegamos a la conclusión que ya adelantaba cuando hablaba de tradición. La tradición cambia básicamente mediante operaciones de inclusión / exclusión de los elementos que proceden del pasado, llevadas a cabo por la comunidad epistémica de participantes para construir en clave de continuidad mundos alternativos en el presente. Estas operaciones van casi indefectiblemente acompañadas con discursos de legitimación ad hoc, que fungen como teorizaciones de los cambios (mediante resignificaciones, anfibologías, 
Outros Tempos, vol. 19, n. 33, 2022, p. 362-382. ISSN: 1808-8031

también inconsistencias o contradicciones) que resultan de estos procesos selectivos y adaptativos de la tradición. Aquí el ejemplo que siempre me viene a la mente es el de las Cortes de Cádiz españolas, y singularmente el Discurso preliminar a la Constitución de 1812, dando cuenta de los cambios sustanciales que ésta introduce sin romper con la clave última del orden tradicional, que es la creencia en un orden natural derivado de la voluntad de Dios y objetivado por la historia.

Creo que las operaciones que normalmente llamamos de "invención de la tradición" consisten en eso. De hecho, yo diría que esta expresión, “invención de la tradición”, es redundante, en la medida que la invención, la manipulación de los elementos procedentes del pasado, parece inherente a la tradición. Por supuesto, lo que no vale es hacer este tipo de operaciones en clave de historia, presentándolo como historiografía: esta se ocupa del conocimiento y no de la invención del pasado. Podemos decir que cabe usar el pasado, y eso es tradición (invención de la tradición), o cabe describir el uso del pasado (la manipulación de la tradición) y eso es historia. Como historiadores del derecho no nos corresponde usar la tradición, sino describir el uso de la tradición.

OT. Un tema clásico de la historiografía brasileña, que tiene una dimensión comparativa evidente, enfatiza las diferencias, de un lado, entre la independencia y la formación del Imperio de Brasil y, de otro lado, entre las independencias y la constitución de los nuevos Estados en la América española. Sus trabajos, no obstante, apuestan por una visión más integrada de las experiencias constitucionales del período. En su percepción, ¿el caso del Imperio brasileño también se puede leer, según esa perspectiva más integracionista, desde un punto de vista normativo, institucional y de prácticas jurídicas?

Carlos Garriga: Sin duda. Yo aquí simplemente me subo a un carro que ya está en marcha desde hace tiempo. Me parece muy claro que esa es una adquisición de la historiografía brasileña, más que de la historiografía del resto de América Latina: creo que son mayores las aportaciones de la historiografía brasileña en pro de una no sé si decir historia conjunta... En todo caso, es más común en Brasil prestar atención a otros espacios americanos que al revés... Aquí se pueden citar distintos nombres, pero valga con el ejemplo de Andréa Slemian, que es un claro exponente de esta manera de ver y concebir las cosas. Creo que esto está calando cada vez más en la historiografía latinoamericana, americanista en general. Hay distintos ejemplos recientes, pero valga con mencionar la historia mínima del 
Outros Tempos, vol. 19, n. 33, 2022, p. 362-382. ISSN: 1808-8031

constitucionalismo en América Latina, de Txema Portillo ${ }^{8}$, que incluye con pleno derecho y en pie de igualdad el mundo brasileño. A pesar de su brevedad, es una obra señera por distintos conceptos (tematización, cronología, etc.), como ya ha sido repetidamente destacado. Y si se me permite una nota personal: junto con colegas de México y Brasil (Rafael DiegoFernández, Andréa Slemian y Mônica Padua), hemos organizado en 2019 y 2021 sendos coloquios bajo el título general Tribunales y cultura jurídica en la América latina colonial, cuyos resultados están pendientes de publicación, que responden a la misma inquietud de afrontar global y comprensivamente el espacio ibero-americano.

En fin, creo que a estas alturas merecería la pena preguntarse si estamos solo ante una aproximación historiográfica en clave comparada, o bien esta aproximación responde a la existencia de un objeto histórico identificable como ibérico. Vaya: si dentro de la tradición jurídica católica hay o no una "tradición jurídica ibérica", justificada por la propia historia conectada de unos espacios contiguos que comparten un mismo universo jurídico-político y muchos tramos de su desenvolvimiento. La pregunta sería, entonces, si cabe algo como una historia conjunta de "los mundos ibéricos" (que por cierto es expresión que da título a un libro reciente y pertinente para esto $^{9}$ ).

Quiero decir que la clave comparada siempre es posible, obviamente: cabe remitir aquí al argumentado alegado del antropólogo Marcel Detienne en favor de "comparar lo incomparable"... E historia sectorial comparada claro que existe, y muy pujante, yo diría: pensemos en una tema tan central como la "segunda esclavitud", con sus focos en Brasil, Cuba y Estados Unidos, objeto de distintos tratamientos comparados desde diferentes ángulos.

Cuando hablamos de historia conjunta postulamos algo más: creo que cabe enfocar la historia de espacios tan contiguos, con tantas interacciones y comparticiones en su decurso, unos espacios tan fuertemente transitivos, a partir de la idea de desarrollos propios de una tradición común, con todo el juego de convergencias/divergencias que ello comporta. Comparar cosas distintas $v$. identificar cosas sustancialmente iguales.

Si vamos al siglo XIX, es decir, al período constitucional, por ensayar alguna acotación que permita mayores concreciones, esto me parece perfectamente posible: todo el aparato conceptual que normalmente utilizamos cuando hablamos de comparación (préstamos, trasvases, modelos, transferencias...), no solo se puede argumentar fácilmente, sino que se

8 PORTILlO VALDÉS, José María. Historia mínima del constitucionalismo en América Latina. Mexico: El Colegio de México, 2016.

${ }^{9}$ Se refiere a: RUIZ IBÁÑEZ, José Javier; MAZÍN GÓMEZ, Óscar. Historia mínima de los mundos ibéricos (siglos XV-XIX). Ciudad de México: El Colegio de México, 2021. 
Outros Tempos, vol. 19, n. 33, 2022, p. 362-382. ISSN: 1808-8031

queda corto para dar cuenta del orden constitucional desde su mismo arranque, a partir de la idea de independencia política sin ruptura jurídica. Esto es algo compartido y sin duda clave. Independencia política sin ruptura jurídica significa que estos espacios jurídico-políticos, las unidades políticas soberanas que resultan de los procesos de emancipación en el mundo ibérico, heredan y hacen suyos todos los problemas de identificación y formulación del derecho característicos del orden tradicional, afrontándolos de una manera similar, que me parece a mí tiene dos claves principales, que pueden formularse sintéticamente como nacionalización del derecho y estatalización de la justicia.

Nacionalización es una palabra muy fuerte, porque parece presuponer la existencia de naciones, algo que la historiografía viene problematizando con toda razón para estos espacios a comienzos del siglo XIX; pero si lo utilizo, siempre a partir del generalizado uso en las fuentes de un léxico "nacionalizante", es simplemente con el propósito de subrayar que el derecho histórico no se mantiene simplemente por inercia (aunque en aquellas circunstancias esto hubiera sido en todo caso así), sino que hay una voluntad política explícita, que cumple al menos el papel de legitimar la continuidad, considerando el derecho tradicional válido en defecto o entretanto no haya sido formulado otro más acorde a las nuevas circunstancias. Creo que este discurso de legitimación es importante, también porque establece las condiciones y los límites de la continuidad (compatibilidad con la Constitución, etc.). Revela, en suma, una percepción de la problemática que la continuidad jurídica plantea. Creo que esto vale para toda América Latina, Brasil incluido desde luego.

La otra medida, igualmente compartida y entiendo que complementaria, es la estatalización del aparato judicial. Sé bien que estatalización es otra palabra demasiado rotunda, por motivos similares: parece presuponer la existencia de un Estado, cuando aquí estamos ante procesos de construcción estatal en el mejor de los casos. Y de nuevo digo que Estado es un término que encontramos constantemente en los textos y con estatalización quiere simplemente significar que quienes tienen la capacidad decisoria en términos normativos (ante todo, las cámaras legislativas) se ocupan ampliamente de diseñar aparatos de justicia cuando menos orgánicamente novedosos: no mantienen simplemente los aparatos existentes sino que los rediseñan, los regulan, en ocasiones los reglamentan con mucho detalle.

Creo que ambas medidas son complementarias y responden a una lógica que puede formularse más o menos así: puesto que el viejo derecho es incontrolable desde las posiciones políticas actuales y no hay posibilidad de renovarlo con presteza (mediante la codificación, que es una empresa política y jurídica compleja), se trata de construir un aparato de justicia 
Outros Tempos, vol. 19, n. 33, 2022, p. 362-382. ISSN: 1808-8031

que responda a los criterios que ahora se consideran imprescindibles, aunque se puede discutir historiográficamente, claro está, cuáles sean estos criterios, su mayor o menor alcance, etc.

Creo que todo esto es perfectamente tratable en términos conjuntos, no solo comparados sino conjuntos: cabe una historia global de una problemática como esta, en buena medida compartida, a saber, la problemática de la determinación del derecho válido en un régimen de derecho no codificado. Mi hipótesis de partida para el mundo latinoamericano en general, incluyendo desde luego Brasil, es que "orden tradicional" y "justicia de jueces" (en los términos que antes decía de ambos) son coextensivos: van juntos y mutuamente se requieren. Por mucho que en el plano discursivo o en los propios textos normativos se pueda postular una justicia legal con sus correspondientes tópicos (uniformidad de la ley, etc.), mientras nos mantengamos en el orden tradicional la justicia sigue siendo de jueces, es decir, sigue cabiendo al juez determinar qué es derecho en atención a las circunstancias del caso controvertido. Esta es para mí la clave, y también el punto de vista desde el que introduzco, si puedo decirlo así, a Brasil en mis preocupaciones y en mis ocupaciones.

Llevo ya un tiempo, como creo que sabes, bregando con las sentencias del Tribunal Supremo brasileño, aunque esto no se haya traducido aún en publicaciones -que espero lleguen pronto. En mi opinión, los tribunales supremos, las Cortes Supremas de Justicia, cumplen una función clave en todo este proceso. En todo este espacio que se declara independiente, las unidades políticas que se postulan soberanas tienen la necesidad política de cerrarse sobre sí mismas, situando en su vértice una instancia que decida en último término, que tenga la última palabra en la resolución de los conflictos que se susciten. Esto se puede hacer de distintas maneras, pero se hace siempre de alguna, y por eso el estudio conjunto de las cortes supremas o la comparación de sus jurisprudencias puede siempre plantearse, a partir de un elenco de problemas compartidos: ¿cuántas instancias? ¿unidad o pluralidad de tribunales supremos? ¿cómo se accede hasta ellos, en virtud de qué recursos: revista, casación, etc.? ¿qué posición jurisdiccional ocupa la Corte Suprema? ¿es obligatoria la motivación de sentencias? ¿cómo se organiza? ¿las sentencias del tribunal deben ser publicadas o no? ¿se considera su eventual trascendencia normativa? En fin, los problemas son siempre más o menos los mismos... De hecho, ahora estoy intentando acabar un breve estudio -a mí me gusta decir conjunto, como he argumentado, pero vale también comparado, si se prefiere: una aproximación comparadaa la primera generación de tribunales supremos de justicia en el Atlántico ibérico, centrándome especialmente en los casos de México y Brasil, que son los que mejor conozco, sin perder de vista los referentes europeos (España y Portugal). Así que sí, mi respuesta es rotundamente afirmativa a esta conveniente y necesaria aproximación comparada. 
Outros Tempos, vol. 19, n. 33, 2022, p. 362-382. ISSN: 1808-8031

OT. Recientemente, usted publicó un artículo (¿Cómo escribir una historia 'descolonizada' del derecho en América Latina ${ }^{10}$ ) en el cual apunta cuestiones y desafíos, en los estudios de historia del derecho, de temas vinculados a la "situación colonial" y a la "subalternización ontológica" de los pueblos indígenas. Teniendo en cuenta que los procedimientos judiciales y los tribunales han sido privilegiados en análisis de esa naturaleza, ¿cómo la historiografía puede abogar con particularidades metodológicas y documentales que les son inherentes?

Carlos Garriga: Como las anteriores, la pregunta va directamente al punto. A bote pronto, empezaría por responder que lo primero que tenemos que hacer es tratar de explicarnos el dato incontestable de la intensa litigiosidad indígena: una constante de la sociedad colonial, plasmada en una muy rica documentación judicial, que es lo que otorga relevancia al espacio judicial como vía de acceso al mundo indígena y nos pone en disposición, y en la obligación, de construir categorías adecuadas para ello. Y con esto subrayo, como desde el principio vengo haciendo, categorías adecuadas a esquivar nuestras preconcepciones, o sea, válidas para descubrir y describir otros mundos. Para esto, ensayo en ese trabajo justamente una aproximación a partir de la historiografía más pertinente, destacadamente Clavero. De hecho, ese texto está concebido y redactado en homenaje a Bartolomé Clavero, a partir principalmente de sus textos. Y esta opción me enfrenta al proceso de colonización y me lleva a hablar de "colonialismo católico", en respuesta a una idea presente en sus textos: él llega a utilizar esta expresión en algún momento, aunque luego no profundice en ella; pero yo diría que responde bien a su idea de fondo.

Aquí se trata de caracterizar el colonialismo impulsado por príncipes católicos, incluido Portugal, como un colonialismo de asentamiento, sin desplazamiento de la humanidad aborigen. Esa es la idea. La clave de ese colonialismo está en la integración subordinada de los pueblos originarios dentro del orden colonial, no la exclusión ni su exterminio, aunque por supuesto hubiera mucho de exclusión y prácticas de exterminio. Pero la clave no está ahí sino en la integración forzada, y la integración implica ubicar el mundo amerindio dentro del orden colonial, claro está que para explotar su fuerza de trabajo, para someterlo al tributo, manteniéndolo siempre en una posición de subordinación: situación colonial, subalternidad ontológica de los indígenas, etc., son expresiones historiográficas que asumo y que me parecen perfectamente válidas para la calificar la realidad colonial.

10 GARRIGA, Carlos ¿Cómo escribir una historia 'descolonizada' del derecho en América Latina? En: VALLEJO, Jesús; MARTÍN, Sebastián (eds.). En Antidora. Homenaje a Bartolomé Clavero. Navarra: Aranzadi, 2019. 
Outros Tempos, vol. 19, n. 33, 2022, p. 362-382. ISSN: 1808-8031

Este camino nos lleva a dos tipos de cuestiones, que se plantean en el curso de otros tantos procesos: el primero, poco atendido por los historiadores del derecho, el segundo tradicionalmente estudiado por la historiografía jurídica.

Las primeras son las cuestiones vinculadas a la evangelización en su sentido más primario, que tienen que ver directa e inmediatamente con la lengua. Siguiendo a los historiadores de estos temas, podemos hablar de conmensuración o inteligibilidad: la evangelización crea las condiciones de posibilidad de una comprensión mutua, siempre desde las posiciones diferenciadas que ocupan colonizadores y colonizados. A eso hace referencia la idea de situación colonial: subrayando la diferencia entre una posición hegemónica y una posición subordinada, pero contemplando la posibilidad de una comprensión recíproca. Estas ideas de conmensuración, de inteligibilidad mutua me parecen fundamentales. Se han planteado en clave religiosa casi siempre, porque las prácticas a las que aluden son siempre funcionales a la evangelización, pero marca todo el desarrollo posterior del orden colonial. John Monteiro hablaba de traducir tradiciones y me parece que esa idea es aquí perfectamente pertinente: de eso es de lo que estamos hablando, algo que va mucho más allá de un problema puramente lingüístico. Y a su vez la evangelización es condición esencial para la integración en o incorporación al orden católico, mediante la asignación -que es paulatina construcción- de un estatus a los llamados indios, como nombre que, más allá de algunas distinciones internas, homogeneiza para los conquistadores toda la inmensa pluralidad y variedad de civilizaciones, de pueblos, de costumbres, etc., El indio como categoría unitaria desde el punto de vista colonial, con un estatus subordinado por definición.

El segundo orden de cuestiones deriva del proceso de institucionalización del orden colonial y se sustancia básicamente en la territorialización inherente a la comprensión jurisdiccional del poder. Todo esto está mucho más trabajado por la historiografía jurídica, que se ha ocupado tradicionalmente de la construcción de aparatos de gobierno y justicia a distintas escalas territoriales. Yo querría simplemente enfatizar la importancia de los tribunales supremos como garantes del orden colonial, aunque no es momento de entrar en esto... Si el primer camino nos lleva a los indios, por este segundo llegamos a las Indias (con mayúscula), el territorio americano. Los indios, unos sujetos coloniales, radicados en las Indias, un espacio asimismo colonial. Por supuesto, a pesar de la generalidad de las denominaciones, unos y otras distan de ser uniformes cualquiera sea el sentido que se considere. 
Outros Tempos, vol. 19, n. 33, 2022, p. 362-382. ISSN: 1808-8031

A mí me interesa especialmente la zona de contacto colonizadores / colonizados (si utilizamos la expresión difundida por Mary Louise Pratt, que me parece válida y oportuna) ${ }^{11}$. Esta zona dista de ser coextensiva con el espacio colonial y tiene uno de sus puntos de referencia, indudablemente, en el ámbito o espacio judicial, tanto laico como eclesiástico, este último con mayor relevancia en el caso luso, creo, si hablamos del mundo indígena.

Creo que es en esta zona de contacto donde debemos fijar la atención si queremos hacernos cargo de la posición de los indios (utilizando su propia expresión) dentro del orden colonial. Pues bien, lejos de visiones simplistas que reducen el derecho colonial a imposición, son patentes en este ámbito también los procesos de adaptación, de apropiación, de resistencia, la agencia indígena, en suma, instrumentalizando en su provecho las reglas coloniales. Y ya que hablamos de resistencia, no creo que se pueda establecer una diferenciación neta entre la resistencia institucionalizada ante las instancias judiciales preferentemente y las resistencias que pretenden incluso cuestionar el orden por vía de rebelión o similares forman parte de un mismo repertorio y encarnan distintas gradaciones de un mismo proceso de adaptación y de resistencia al orden colonial.

Todo este preámbulo me sirve para decir que, como historiador necesariamente ubicado en un punto de vista externo, no me parece muy fructífero aislar el mundo indígena, reconstruir sus claves al margen del orden colonial. Desde este punto de vista, no se trata de reconstruir una suerte de tradición primordial que remonte a tiempos prehispánicos, como tampoco se sostiene que la tradición castellana, en el caso hispano, y portuguesa, en el caso brasileño, se traslada sin más a este territorio y la podemos identificar en esta o en aquella institución o procedimiento o mecanismo regulador. Lo que define al mundo colonial es justamente la conmistión de lo uno y lo otro, así que en clave historiográfica me parece desacertado intentar separar la tradición indígena y la novación hispana: al contrario, interesa caracterizar la conmixtión, la mezcla, el conflicto, el choque violento o institucionalizado entre unas y otras. En este sentido, me parece importante prestar atención a la categoría "cultura jurídica colonial", que se encuentra tan frecuente como inopinadamente en la historiografía (sobre todo anglosajona) de los últimos años.

Una de mis últimas líneas de trabajo pasa justamente por aquí y trata de dotar de un contenido preciso a esta expresión, "cultura jurídica colonial”, dando siempre por supuesto que el punto de partida es la convivencia / conflicto, bajo un mismo orden, de colonizadores/colonizados en posición hegemónica y en posición subordinada, que se desenvuelve de manera especial

\footnotetext{
${ }^{11}$ Se refiere a: PRATT, Mary Louise. Imperial Eyes: Travel Writing and Transculturation. London: Routledge, 1992.
} 
Outros Tempos, vol. 19, n. 33, 2022, p. 362-382. ISSN: 1808-8031

(como está muy constatado) en el espacio judicial, que como antes recordaba es un espacio fuertemente formalizado, ritualizado: el espacio judicial no es cualquier espacio y la dinámica procesal que en él se desenvuelve no es cualquier dinámica social... Tiene sus características propias. Es un espacio densamente reglado, por reglas que son por supuesto instrumentalizables, pero con ciertas condiciones de uso, por decirlo así, que si el historiador quiere entender debe conocer, desde luego.

Y ahí nos encontramos, este sería el tercer elemento, con la idea de localización, a la que antes hacía referencia, que pone el foco en los procesos de intermediación locales que operan en la determinación del derecho y sigue el actuar de los agentes, provistos de sus propias constelaciones cognitivas y axiológicas (ideas, valores, creencias, etc.), que operan como razones para la acción. Interesa prestar atención aquí a la manera como se determina el derecho, a partir de la interacción - con toda su gama de posibilidades- entre una cultura hegemónica y otras culturas fuertemente presentes, como son las culturas de los pueblos originarios en el marco del orden colonial...

Creo que esto puede expresarse muy bien a partir de una idea de la historiadora norteamericana Yanna Yannakakis, estudiosa de la problemática indígena en la Oaxaca colonial $^{12}$, a propósito de la traducción, que creo se puede trasladar bien al mundo del derecho: es en el espacio judicial, ya antes aludí a ello, donde el orden global de impronta católica y vocación hegemónica es vernaculizado y las circunstancias locales de los indígenas son articuladas de maneras inteligibles para los colonizadores. Creo que es aquí y sobre esta base como puede reconstruirse una cultura jurídica colonial.

Un último apunte. Cuando digo que no se trata de la reconstrucción de tradiciones primordiales, me refiero a nuestra labor de historiadores, dejando por supuesto a salvo los procesos identitarios que podemos calificar de etnogénesis de parte indígena, en continuidad o para la reconstrucción/recreación presente de sus propias tradiciones como pueblos (desde el presente hacia el pasado, digamos). Creo que este es un buen ejemplo de lo que antes decía: los participantes (los agentes) usan la tradición, los observadores (los historiadores) describen el uso de la tradición.

\footnotetext{
12 Entre otros: YANNAKAKIS, Yanna. The Art of Being In-between: Native Intermediaries, Indian Identity, and Local Rule in Colonial Oaxaca. Durham: Duke University Press, 2008.
} 